\title{
Darwin's “Mr. Arthrobalanus": Sexual Differentiation, Evolutionary Destiny and the Expert Eye of the Beholder
}

\author{
RODERICK D. BUCHANAN
}

History and Philosophy of Science Unit

School of Historical and Philosophical Studies

The University of Melbourne

Parkville, VIC 3010

Australia

E-mail:rdbu@unimelb.edu.au

\begin{abstract}
Darwin's Cirripedia project was an exacting exercise in systematics, as well as an encrypted study of evolution in action. Darwin had a long-standing interest and expertise in marine invertebrates and their sexual arrangements. The surprising and revealing sexual
\end{abstract}


differentiation he would uncover amongst barnacles represented an important step in his understanding of the origins of sexual reproduction. But it would prove difficult to reconcile these findings with his later theorizing. Moreover, the road to discovery was hardly straightforward. Darwin was both helped and hindered by the tacit expectations generated by his transformist theorizing, and had to overcome culturally-embedded assumptions about gender and reproductive roles. Significant observational backtracking was required to correct several oversights and misapprehensions, none more so than those relating to the chronically misunderstood "Mr. Arthrobalanus." With careful attention to chronology, this paper highlights some curious and overlooked aspects of Darwin's epic project.

Keywords: Darwin, cirripedes, invertebrates, sexual differentiation, sexual selection

"She walked up to me and she asked me to dance..."

Lola, Ray Davies

Combing the intertidal shoreline at Bahia Low on the Chonos Archipelago in southern Chile, a 25-year old Charles Darwin picked up the empty shell of the edible mollusk Concholepas peruviana (syn.: Concholepas concholepas). It had caught the attention of the young naturalist due to the small cavities it displayed, one of many such shells that were "almost completely drilled" in this manner. Recording his observations on 8 January 1835, Darwin found a tiny orange organism inside these cavities, an organism he recognized as a barnacle. But it was a strange barnacle indeed, unlike any he had ever encountered. Many years later, this "illformed little monster" would set off a marathon eight-year study. ${ }^{1}$

Darwin's barnacle project occupied a lengthy interregnum between his 1844 essay detailing an almost fully realized theory of evolution, and finally going public with it in 1859 with The Origin of Species. Historians had initially tended to dismiss the project as an arcane and inexplicable detour. But concentrated attention to Darwin's journals, notebooks and correspondence demonstrated that Darwin had a long standing interest in marine invertebrates, particularly their procreative systems. ${ }^{2}$ However, it was his thorough-going overhaul of the Cirripedia that was his crowning achievement in the area.

1 See Keynes, 2000, pp. 274-277, p. 276, for Darwin's original specimen description.

2 Winsor, 1969; Crisp, 1983; Hodge, 1885; Sloan, 1985; Richmond, 1988; Love 2002; Castilla, 2009; Deutsch, 2010; Mannouris, 2011. 
On face of it, Darwin's barnacle project was a hugely exacting exercise in systematics. But an abiding curiosity in the reproductive arrangements of these little sea creatures ran like a scarlet thread through the dry taxonomic descriptions. The strange varieties of sexual differentiation Darwin would uncover would amaze and thrill him. While Darwin had already sketched out a transformist framework for this process, the barnacles provided a revealing but paradoxical set of instantiations that would sit rather uneasily with his later theorizing. In the distance, the barnacles gestured toward even more profound questions about the mysterious origins and myriad effects of sexual reproduction.

And it all started with the Chilean specimen Darwin misleadingly (and rather impolitely) dubbed "Mr. Arthrobalanus." But to explain how this came about we much track back several decades to the turn of the $19^{\text {th }}$ century.

\section{Overture}

Much had changed about the way naturalists viewed invertebrates in the lead up to Darwin's epic Beagle voyage of the early 1830s. Lamarck had recently overturned the ancient assumption that the primitive invertebrates were unimportant, degraded forms, the left-overs of creation. The Frenchman had up-ended a world-view that stretched back through Curvier, Buffon, Linnaeus and Aristotle by suggesting that life should be studied from the bottom up, from the simple to the complex. ${ }^{3}$

Even in his callow youth, Darwin had a keen appreciation of these shifting intellectual currents. During his Edinburgh years in the mid-1820s, Darwin came into contact with Robert Grant, a physician and part-time lecturer in comparative anatomy. Grant's investigations focused on marine invertebrates, particularly the plant-like animals known at the time as "zoophytes," which includes sponges and corals. ${ }^{4}$ Grant saw the invertebrates as instructive biological examples, simplified models of the more complex processes of higher forms. Darwin quickly came to share Grant's interests and would accompany him on collection trips.

Grant was a leading figure in the Plinian Society, a local natural history group. Darwin presented his first scientific paper to this group on 17 March 1827, suggesting that the ovarian eggs of the bryozoan Flustra foliacea, a moss-like marine invertebrate genus, used cilia for locomotion, and that the black spots on the shells of oysters were the eggs of the marine leech Pontobdella muricata. ${ }^{5}$ Grant had set up these investigations and was not particularly generous about giving Darwin the credit for what he found. A sense of rivalry developed between the

\footnotetext{
${ }^{3}$ Lamarck, 1801.

${ }^{4}$ It takes in groups presently classed as Gorgonia, Porifera (a name Grant coined, which includes sponges) and Anthozoa (which includes corals).

${ }^{5}$ Rainbow, 2011.
} 
budding naturalist and his older mentor. Darwin bridled at Grant's more radical views. Grant accepted the controversial Lamarckian notion that the taxonomic ordering of the complex to the simple represented the historical order of the appearance of life on earth. And Grant went further than Lamarck in searching for analogies between the plants and animals, with a potentially universal set of natural laws governing both kingdoms. At this stage, Darwin remained indifferent to Lamarckian transmutation. He left Edinburgh and a medical career behind in 1827, still entertaining the more orthodox opinion that a biochemical chasm separated plants and animals. ${ }^{6}$

By the time Darwin boarded the Beagle in 1831, he was well prepared for the collection and microscopic analysis of marine invertebrates. His knowledge of this group probably surpassed that of any other. Robert Brown had advised him on the purchase and use of a suitable shipboard microscope. Several London experts had instructed him to pay special attention to unusual and novel forms. During the voyage, Darwin spent much of his time collecting and analyzing marine invertebrates, and viewed his work in this area as second only to his geological observations. The classificatory challenges presented by the many new specimens he encountered helped set him on a career as a naturalist.

Safely back in England in 1836, Darwin continued his research on the zoophytes and suddenly came to see strong analogies between plant regeneration and animal reproduction that could unite the two kingdoms and their potentially common branching histories. ${ }^{7}$ This epiphany presaged an enormous shift in Darwin's thinking. The accumulated evidence of biogeography and Lyellian geology, and the notion of Malthusian struggle, pushed Darwin toward transformism. His 1838 transmutation "Notebook D" showed him to be pondering analogies between plants and animals, and sifting through ideas about sexual differentiation. Taking up John Hunter's suggestion that the development of all organisms was "subject to hermaphroditism," Darwin sketched out a transformist framework for the emergence of sexual differentiation: separate sexes arose from ancestral hermaphrodite forms with the organs of one sex or the other gradually becoming "abortive." But he was still vexed by the particular course it might take for each species and why "highness in scale [had] no constant relation to separation of sexes." 8 Darwin wondered why equivalent abortion was not observed in each sex (e.g., why men still had nipples but no trace of a womb or ovaries, or why women had no trace of testicles) Darwin also chewed over Hunter's notion of primary and secondary sex characteristics and how one might explain the latter, a problem he later addressed with his theory of sexual selection in The Descent of Man. And here in "Notebook D," Darwin famously deduced that life on earth first started in the sea, with liquid semen the remnant of these aquatic origins. Darwin noted that the genesis of sexual differentiation was a key problem any theory of

\footnotetext{
${ }^{6}$ Sloan, 1985.

7 Ibid.

8 “Notebook D" (D, from Barrett et al., 1987, p. 156).
} 
species origins had to address. Darwin reminded himself to allude to sexual differentiation as a particular difficulty, and to cite speculative explanations to show that it was not an insurmountable hurdle.

The invertebrates played a small but crucial role in his emerging account of the origin of species, featuring at various places in Darwin's post-Beagle transmutation notebooks as an intriguing, ambiguous group. In his unpublished 1844 essay, Darwin contrasted the motility of their early life cycle with their plant-like sessile adult forms to illustrate why a developmental perspective was crucial to proper taxonomic classification.

Given Darwin's expertise and experience with marine invertebrates, it was indeed curious that he had published very little about them up to $1846 .{ }^{9}$ This void would be more than filled by the barnacle project, which grew out of the last of his Beagle-related publications dealing with invertebrates. This was planned to be part of the Treasury-supported Zoology series, but a funding shortfall saw Darwin take on the task independently. ${ }^{10}$

Before commencing, Darwin was well aware of the debate surrounding the proper classification of invertebrates in general, and cirripedes in particular. Most naturalists, Linnaeus and Curvier included, had situated cirripedes with Mollusca, although Lamarck did not. Hercule StrausDurckheim was the first to propose they were related to crustacea in $1819 .{ }^{11}$ In the early 1830 s, John Vaughan Thompson's important observation of their metamorphosis from motile larval forms confirmed these affinities, as did the subsequent work of Hermann Burmeister, who clarified the two-stage, nauplius to cypris developmental sequence. ${ }^{12}$ As a result, cirripedes were tentatively reclassified under Articulata.

Darwin had read Thompson's Zoological Researches early in the voyage and followed their practical pointers on collection methods. He was also up to date on comparative anatomy and systematics, including Richard Owen's ideas about divergence from archetypes and William MacLeay's quinarian classification system. ${ }^{13} \mathrm{He}$ had fully absorbed the methodological perspective of zoologist Henri Milne-Edwards, who emphasized the importance of embryology for identifying homologies, and of entomologist Gaspard Auguste Brullé, who suggested the

\footnotetext{
${ }_{9}^{9}$ Love (2002) makes this point persuasively.

${ }^{10}$ Darwin told Hooker on 2 October 1846 that this would be a short-term study of a limited set of "lower marine animals" that would take "some months, perhaps a year." CCD 3, 346 (i.e. volume three, p. 346 of Darwin's edited correspondence).

${ }^{11}$ Straus-Durckheim, 1819.

12 Thompson, 1828-1834, 1835a, 1835b; Burmeister, 1834. These works outlined the still-accepted idea that there are two larval stages for common barnacles: nauplius and cypris. In the nauplius stage the organism swims freely like zooplankton, molting many times before becoming cypris larvae. Cypris larvae do not eat but search for a good surface to cement on. They attach themselves by their antennas and within hours become mature adult barnacles with a shell.

${ }^{13}$ MacLeay, 1819-1821; Owen, 1843.
} 
most complex and characteristic organs in a group were the first to develop in each individual. This made an organism's developmental sequence a key taxonomic indicator. ${ }^{14}$

In many respects, barnacles were a natural fit for Darwin. They were relatively simple in organization and that made them a useful analytic model, the kind of instructive exemplar Robert Grant advocated. They were also known to be widely distributed and highly variable (although Darwin would be surprised at just how variable they proved to be). Moreover, they had a transitional quality that gave them an obvious evidential potential for a naturalist developing a comprehensive account of speciation. And they were of a size that was easy to manage as a home-based researcher.

\section{Barnacle Beginnings}

Much of Darwin's persistence with the barnacles, especially the way the project expanded beyond its initial small scope, can be explained by the peculiar qualities of the "little monster" he picked up on the Coast of Chile and the incomplete nature of Cirripedia taxonomy at the time. Darwin had effectively uncovered a new kind of barnacle. Common in South American waters, this species had remained undescribed by European naturalists largely due to the location of its habitat. Darwin collected many shells containing specimens, although he would later lose a number of them.

Darwin had assigned his novel specimen to the common rock-dwelling Balanidæ family, even though it had no shell. It was tiny (about $2 \mathrm{~mm}$.), the smallest cirripede known at that time. It apparently bored or burrowed its way into its host shell - something he noted at time as a particularly unusual feature that would become a defining characteristic of the order he would establish for it. He would eventually conclude that it achieved this by mechanical means rather than a solvent (as did the Verrucae cirripedes). ${ }^{15}$ Darwin partially realized the novelty of his specimen in 1835, and recorded his observations on its larval stages and their resemblance to the metamorphoses of Crustacea - an affinity that was still a matter of dispute at the time. ${ }^{16}$

Darwin had initially named his Chilean specimen Arthrobalanus (meaning "jointed Balanus," Balanus being the genus of the common acorn barnacle). He playfully anthropomorphized his specimen with the nickname "Mr. Arthrobalanus." But this "singular little fellow" did not square with the Balanidæ family which included all the common sessile, acorn barnacles that tend to cover rocks. ${ }^{17}$ To ascertain its unique features and its affinities with related species,

\footnotetext{
${ }^{14}$ Richmond, 1988.

15 This feature had played on Darwin's mind in the interim. In his 1837 "Edinburgh Notebook" (EN, from Barrett et al., 1987, pp. 475-476) Darwin had noted an article by Edward Osler which treats, "the mechanism by which the boring and burrowing shell fish form their habitations ..." Osler, 1826, p. 342. 16 See Keynes, pp. 274-277.

17 C.R. Darwin to J.D. Hooker, 26 October 1946, CCD 3, 357.
} 
Darwin had to survey the Cirripedia more widely and even look beyond the group. The descriptive literature was obviously incomplete, so this comparative task had to be done on a first-hand basis. Tentatively at first, Darwin set about garnering specimens from colleagues, Owen one of the first amongst them. ${ }^{18}$ In time Darwin would develop a formidable network of suppliers and informants. But at this early stage, the project grew on a piece-meal basis, with Darwin examining and describing specimens as they came to hand, rather than systematically working through particular taxa. ${ }^{19}$

\section{Sizing up "Mr. Arthrobalanus"}

Darwin was clearly sensitized to the issue of sexual differentiation from the beginning, since it related to one of the talking points regarding Cirripedia. While embryological studies had linked them to Crustacea, such a classification faced at least one major problem: Crustacea generally displayed separate sexes. In contrast, cirripedes had been observed by Cuvier, Hunter and others to be hermaphrodites, although there was still much confusion and uncertainty over the structure and function of their reproductive organs. ${ }^{20}$ Darwin had noted this classificatory paradox in his "Edinburgh Notebook," remarking that "The Sexual system of the Cirrhipedes is the more remarkable from their alliance to Articulata, which are all truly bisexual."21 Thompson himself was unconvinced that all Cirripedia were hermaphrodite, pointing out that in many other Crustacea the males of the species are smaller and quite distinct, and only observed at certain times of the year.

So there was an expectation (or hope) amongst naturalists that separate sexes might be found in some cirripede species to shore up this new classification of the group. Some went to great lengths to support this view, none more so than Henry D.S. Goodsir. Goodsir was a physician and zoologist specializing in Crustacea, and a friend of Darwin's confidant Joseph D. Hooker. Goodsir was much taken by Thompson's work. In a 1843 paper, Goodsir pushed the idea of bisexualism amongst cirripedes, describing what he thought was his discovery of a small male residing in the sack of what he thought was the female Balanus balanoides (syn.: Balanus elongatus). So why had this male of a common barnacle species not been observed before? With quaint Victorian terminology, Goodsir suggested that, like some other Crustacea, the male of

\footnotetext{
18 See C.R. Darwin to R. Owen, 25 November 1846, CCD 3, 272-273.

19 Anderson and Lowe, 2010.

${ }^{20}$ For example, Karsten (1845) had described the testes of the Balanus as "hepatic organs." Goodsir (1843) also noted the confusion over the sexual anatomy of Cirripedia in the writings of Cuvier and Hunter. In Living Cirripedia, Volume II, Darwin corrected the Von Siebold and Stannius 1849 compendium Anatomie Comparée. They considered the articulated probosciformed penis to be an elongated abdomen, which Darwin admitted was "a view which, at the commencement of my examination, I was tempted to admit..." Darwin, 1854, p. 66. See also Hunter, 1840.

${ }^{21}$ Darwin, EN 60.
} 
the species only became visible during "seasons of love."22 Goodsir went on to report that this male was in turn infested with a new isopod parasite of the "family Ioniens of M.Edwards." 23

Despite the gendered moniker that Darwin gave "Mr. Arthrobalanus," he initially examined it under the assumption it was a hermaphrodite. ${ }^{24}$ But looking at the reproductive structures of his Chilean specimen and expecting to see twin sets, Darwin was perplexed. It seemed that while it did have "detached" ova, it had no ovisac. Nor did it appear to possess a probosciformed penis, as other hermaphrodite Cirripedia did. ${ }^{25}$ However, Darwin found two internal ringed appendages on one specimen, and he presumed they had a reproductive function. In effect, he thought "Mr. Arthrobalanus" had two penises. But as Darwin commented to Joseph Hooker on 12 November 1846, he thought he had found an additional "abortive anterior penis" in another species he had examined, so that brought the gratuitously-endowed "Mr. Arthrobalanus" "into bounds." 26 So we see that sexual differentiation was at the forefront of Darwin's mind and observational set, even at this early stage. The phrase "abortive anterior penis" was a key indicator of this. Nonetheless, Darwin did not know whether he would find such differentiation, or what form it might actually take.

Darwin completed his initial examination of "Mr. Arthrobalanus" late in 1846. He drafted a short paper on its anatomy. He was obviously not happy with it, however, for it never saw the light of day. At this point, Darwin put his "little monster" aside, and went in search of more specimens in order to make more effective appraisals. He continued to gather and analyze new specimens as they came to hand. His progress was slow, as he was periodically stricken with illness and often preoccupied by other things. But by late in 1847, Darwin finally heeded the urgings of his colleagues and decided to take on the whole group. Certainly the need for broader comparisons was one reason he did this. More practically, John Gray made him an offer that he eventually felt he couldn't refuse: the use of Gray's own collection and that of the British Museum's. Once Darwin set himself up to do the whole group, he was in it for the long haul.

${ }^{22}$ Goodsir, 1843, p. 95. In this same journal issue Louis Agassiz outlined his sensational Ice Age theory. See also Goodsir, 1844.

${ }^{23}$ H. D. S. Goodsir, 1843, p. 96.

${ }^{24}$ According to Crisp (1983), Darwin was adept at recognizing and describing the reproductive structures of these creatures even at this stage, although he suggested Darwin had more trouble with female rather than male organs, ova ducts in particular. But as we will see, when it came to "Mr. Arthrobalanus" he had problems with both.

${ }_{25}$ Contra Stott (2003), Darwin stuck with his initial assumption that "Mr. Arthrobalanus" was a hermaphrodite almost to the end of the project. Darwin recalled that in his original Beagle notes, he had observed that the ova of his Chilean specimen appeared perfectly detached. However, he would later change his mind about the missing ovisac. See Darwin, 1854, p. 579.

${ }^{26}$ C.R. Darwin to J.D. Hooker, 12 November 1846. CCD 3, 365. Darwin's observation of a second abortive anterior penis in another species was possibly a mistake. I could find no mention of such a structure in Darwin's later volumes. In his summary in the second volume of Living Cirripedia, Darwin otherwise affirmed that both male and hermaphrodite barnacles possess only one penis. See Darwin, 1854, p. 9. 
While the search for sexual differentiation might also have also motivated him to extend his study, he had not found such differentiation in his cirripedes prior to committing to do the whole group.

\section{Correcting the Luckless Mr. Goodsir}

Darwin was probably well aware of Henry Goodsir's work in the early stages of the project. He had certainly read Goodsir's paper on the sexually differentiated Balanus balanoides by late 1847.27 But he would be less than persuaded by it, for it did not alter his view that cirripedes were generally hermaphrodites. A month before committing to the whole group in December 1847, we know that Darwin had examined Balanus specimens comparable to those of Goodsir. His conclusions might have devastated Goodsir, if not for the fact that Goodsir had already perished as assistant surgeon and naturalist on the ill-fated Franklin expedition. Darwin was adamant that Goodsir's 'male' Balanus was nothing of the kind. According to Darwin, the organism residing in the sack of the 'female' Balanus belonged to any entirely different species. Darwin described it as "Lernæa like," without being able to definitively identify it. ${ }^{28}$ This was the female of the species, Darwin wrote, while Goodsir's 'parasites' were actually the smaller larvæ of this same species. Darwin also found:

a little perfect or mature crustacean animal, something like the larvæ, this I suspect may be the male of the Lernæa. If, then, my conjectures are correct (\& I beg to observe that I have only cursorily looked at these specimens) I have the male, female \& the larvæ in different states, of this singular Lernæa like animal, which is parasitic on Balanus. ${ }^{29}$

Commonly called anchor worms and parasitic on freshwater fish, Lernæa was a type of crustacean whose proper classification was as contentious as that of the Cirripedia. While

\footnotetext{
${ }^{27}$ Contra to the uncertainties of Love (2002, p. 281, fn. 167), we can be fairly sure Darwin had actually read Goodsir's work by the early stages of the project. As Love noted, both volumes of the Edinburgh New Philosophical Journal containing Goodsir's 1843 and 1844 articles were in Darwin's personal library, although he did not mention reading them in his reading notebooks. Darwin's correspondence with Hooker showed he was well aware of Goodsir's reputation by 1844 . Hooker mentions him in passing, 8 November 1844 (CCD 3, 76). Before Goodsir left on the Franklin expedition in 1845, Darwin had instructed Goodsir to make various observations about "icebergs and boulders \&c. \&c." See Darwin to Hooker, 16 April 1845 (CCD 3, 177). Darwin also told Hooker in late October 1846 that he had "read heaps" of material on barnacles. Surely Goodsir's key papers were amongst these, if he had not already read them by then. We know for certain he has read them by November 1847 when he compares his observations to that Goodsir.

${ }^{28}$ Darwin describes these observations while introducing himself to the renowned Henri Milne-Edwards on 18 November 1847, CCD 4, 96-97.

29 Ibid., p. 97.
} 
Goodsir had noted that his 'male' Balanus did resemble a Lernæa, it seemed his keenness to confirm sexual differentiation within Cirripedia got the better of him.

By 1850, Darwin had decided it was more accurate to describe Goodsir's 'male' Balanus and parasite species as an unidentified species "allied to Bopyrus," which was another recently cataloged form of Crustacea. ${ }^{30}$ And this was how he described this species in his 1851 Living Cirripedia, Volume I. ${ }^{31}$ It is now known as Hemioniscus balani, an isopod crustacean situated in the suborder Epicaridea (and thus indeed allied to the Bopyridae family). It is widespread in temperate waters such as the North Atlantic, and is notorious as a parasitic castrator of adult barnacles. ${ }^{32}$ However, in this case it was the unfortunate Goodsir who was getting his credentials clipped, and not for the last time. As he definitively surveyed the group, Darwin would correct several more of his late colleague's observations, and those of many others.

While Goodsir's 'male' Balanus balanoides was a false alarm as far as sexual differentiation went, it may have primed Darwin's observational set. As Goodsir had noted, Lernæa males were known to be significantly smaller and less developed than their female counterparts to which they would (apparently voluntarily) cling. ${ }^{33}$ Such global disparities in male/female form are now grouped under the term "sexual dimorphism." For Darwin, this was first-hand experience with the kind of pronounced sexual differentiation some Crustacea exhibited. This episode also highlighted the complicated biological environment Darwin was dealing with as he felt his way through barely charted taxonomic territory. In such an environment, parasitic, epizoic and symbiotic relationships were a common and confusing feature amongst allied organisms. It was a feature that would try the most expert eyes in the field, including Darwin's.

\section{Devilish Discovery}

30 C.R. Darwin to A. Hancock, 26 January to March 1950, CCD 4, 307-308.

${ }^{31}$ Darwin (1851, p. 55) wrote that this "new parasite which is allied to Bopyrus, in structure, is likewise allied to it in habits, living attached to Cirripedia, a sub-class of the crustacea."

${ }^{32}$ The reader might now think that the castrating propensity of Hemioniscus balani might explain why Goodsir thought the hermaphrodite Balanus it had attached itself to was a female. But Hemioniscus balani fixes to the wall of the ova of its barnacle host - exactly the position Goodsir observed it to be attached. It sucks out the ovarium fluid, preventing egg development without impairing sperm production, effectively turning a hermaphrodite barnacle into a male. It seems that Goodsir's suggestion that the larger host Balanus was actually a female rather than a hermaphrodite was based on a more general, if confused, interpretation of its reproductive organs rather than a specific dissection of the specimen in question. For some relatively recent science on Hemioniscus balani see Blower and Roughgarden, 1988. ${ }_{33}$ Citing analogies, Darwin (1851, p. 200) observed: "in the same class with the Cirripedia, there is a whole family of crustaceans, the Lerneidæ, in which the males, compared with the females to which they cling, differ as much in appearance as in Ibla, and are even relatively smaller..." 
However, early in 1848 came a series of discoveries. On April 1 Darwin announced to old friend and mentor John S. Henslow that he had found in one genus (we can safely assume it was Ibla) some small, apparently parasitic males. ${ }^{34}$ Even more exhilarating news would follow a few weeks later. He told close confidant Joseph D. Hooker that not only had he

lately got a bisexual cirripede, the male being microscopically small \& parasitic within the sack of the female; I tell you this to boast of my species theory, for the nearest \& closely allied genus to it is, as usual, hermaphrodite, but I had observed some minute parasites adhering to it, \& these parasites, I now can show, are supplemental males, the male organs in the hermaphrodite being unusually small, though perfect \& containing zoosperms: so we have almost a polygamous animal, simple females alone being wanting. ${ }^{35}$

A male accompanying a hermaphrodite, as opposed to a female, was an extraordinary discovery. While known to exist in plants at the time, as Darwin noted in Living Cirripedia, Volume I, no one had observed this form of partial sexual differentiation in the animal kingdom. ${ }^{36}$ With typical understatement, Darwin would announce this as a "new fact." ${ }^{37}$ Historians have highlighted this episode as a thrilling confirmation his notebook conjectures, given that Darwin was at pains to emphasize to Hooker that his species theory was central to this discovery:

I never sh ${ }^{d}$ have made this out, had not my species theory convinced me, that an hermaphrodite species must pass into a bisexual species by insensibly small stages, \& here we have it, for the male organs in the hermaphrodite are beginning to fail, \& independent males ready formed. But I can hardly explain what I mean, \& you will perhaps wish my Barnacles \& Species theory al Diabolo together. But I don't care what you say, my species theory is all gospel..$^{38}$

This letter to Hooker has been repeatedly quoted by Darwin scholars for the 'eurêka' moment it conveyed, and as evidence of Darwin's growing confidence in his yet-to-be-published species theory. But there is another entirely different aspect worth highlighting. Several details in this 1848 letter to Hooker do not quite tally with Darwin's account in Living Cirripedia, Volume I three years later. Part of the problem here is that Darwin did not always make it clear which species he was referring to in his correspondence during this period. This is understandable; at this stage he had not necessarily formally situated and named the specimens he was examining. The editors of Darwin's correspondence suggested that it was Ibla cumingii he was referring to with Henslow, and that he was linking his findings in this species with the even more sensational discovery of the hermaphrodite-male paring in the Scalpellum genus. I think they are correct in both cases. Ibla cumingii was an undescribed species that the wealthy conchologist Hugh Cuming had collected in the Philippines on one of his many colonial adventures. Cuming had

${ }^{34}$ C.R. Darwin to J.S. Henslow, 1 April 1848, CCD 4, 127-128.

${ }^{35}$ C. R. Darwin to J. D. Hooker, 10 May 1848, CCD 4, 138-140.

${ }^{36}$ See Crisp, 1983; Richmond, 1988.

${ }^{37}$ Darwin, 1851, p. vi.

${ }^{38}$ C. R. Darwin to J. D. Hooker, 10 May 1848, CCD 4, 140. 
donated his specimen collection to Darwin; thus Darwin returned the favour by naming this species in Cuming's honour.

But here is where things get tricky. In Living Cirripedia, Volume I, Darwin told of first dissecting the common species Scalpellum vulgare (syn.: Scalpellum scalpellum) and being surprised at the almost constant presence of very minute parasites. At the time - probably late December 1847 to early January 1848 when he first started working through the pedunculated cirripedes - Darwin concluded they belonged to some new class or order amongst Articulata. Darwin then added:

Many months afterwards, when I had seen in Ibla [March - May 1848], that an hermaphrodite could have a complemental male, I ... resolved to look with care at these parasites; on doing so, I soon discovered that they were Cirripedes. ${ }^{39}$

So if Darwin's award-winning published volumes are anything to go by, he actually first discovered the stunning hermaphrodite-male paring in the Ibla genus. This is quite plausible in itself: the two Ibla species he catalogued were a female-male pairing (Ibla cumingii) and a hermaphrodite-male pairing (Ibla quadrivalvis). Yet Darwin's 1848 letter to Hooker gives the distinct impression of the excited initial discovery of this hitherto unknown hermaphroditemale pairing. And this discovery was all due to his species theory, Darwin boasted. Even so, Darwin told Hooker he could hardly explain what he meant, suggesting that there was more to the story than he was letting on. The editors of Darwin's correspondence either did not notice or ignored the apparent contradictions. And so has everyone else as far as I am aware. How do we reconcile them?

There are two reasonable possibilities in addition to a number of implausible ones. ${ }^{40}$ The first is that the account in Living Cirripedia is correct but the species Darwin was referring to in his

39 Darwin, 1851, pp. 231-232.

${ }^{40}$ One implausible possibility is that the account given in Living Cirripedia is correct and that these were the two Ibla species Darwin was referring to in his letter to Hooker. However, we must then accept that Darwin was being improbably careless with his use of the word "genus" with Hooker, that he had actually turned to the nearest species and found a hermaphrodite-male pairing. But this also makes his species theory input claim seem strange. Why did he think it was such a crucial part of a process that would seem to simply involve doing one species of a genus after another? Moreover Darwin's description of Ibla quadrivalvis in Living Cirripedia did not match the description of the hermaphrodite-male pairing he provided to Hooker. Only one (relatively large) male tended to be attached to the hermaphrodite Ibla quadrivalvis specimens, not the multiple number of "minute parasites" Darwin wrote of to Hooker. This brings us to a second implausible possibility. Again we might assume that Living Cirripedia is correct, but that the two species he was referring to with Hooker were Ibla quadrivalvis and Scalpellum vulgare. In this case, both species he was referring to in his letter were hermaphrodite-male parings. Darwin was then making much more of his discovery of a hermaphrodite-male pairing in a related genus than his initial discovery of such a pairing per se - which would be very odd. Much depends on the interpretation of the word "bisexual" to describe the first species in his letter to Hooker. The editors suggested Darwin was using it to denote separate sexes, departing from his "usual" usage. But there was no usual sense of the 
correspondence with Hooker were Ibla cumingii (a male and female pairing) and Scalpellum vulgare (a hermaphrodite-male pairing). Darwin had first spotted complete sexual differentiation in Ibla cumingii, as he reported to both Henslow and Hooker. Soon after, however, he apparently came across a more unusual kind of partial differentiation in Ibla quadrivalvis. And then he confirmed a similar kind of pairing when he re-examined Scalpellum vulgare, the first of the Scalpellum species he tackled..$^{41}$ But this all makes his breathless letter to Hooker a little hard to fathom. If his later published account is to be believed, Darwin had already found a hermaphrodite-male pairing in Ibla, but neglected to tell his closest confidant. And given this straightforward observational precedent, why did Darwin tell Hooker that his species theory was such a crucial part of the discovery process? Surveying Darwin's correspondence from 1848 to 1851 half suggests he didn't get to Ibla quadrivalvis until well after Ibla cumingii. ${ }^{42}$ Certainly we know that in the middle of 1851, nearing the publication of his first volume, Darwin was still hurriedly searching for additional Ibla quadrivalvis specimens. ${ }^{43}$ This species was not easy to come by, for its native habitat was southern Australia. The only wellpreserved example of an Ibla quadrivalvis male came from Kangaroo Island, probably courtesy of the British Museum. In contrast, Scalpellum vulgare specimens were far more plentiful. Darwin's growing network kept him well supplied with this locally-common species. And since they

term "bisexual" in Darwin's work. He used it in wildly inconsistent ways, sometimes to denote hermaphroditism, sometimes to denote separate sexes. Scanning his publications and correspondence reveals no clear pattern in his usage. He used it to denote separate sexes in his 1842 species sketch and in drafts of Natural Selection, but appeared to use it in both senses in his four barnacle publications at various points. Thus context is crucial to deciding which way he meant it (but even then it is not always clear). In his letter to Hooker, Darwin appeared to be making a clear contrast between the species he was referring to, using the unambiguous term "hermaphrodite" to describe the surprising features of the second species. I think the editors were otherwise correct about Darwin's usage in this case; it seems he meant "bisexual" as in "separate sexes." So we can discount this second possibility as well.

${ }^{41}$ Darwin would discover hermaphrodite-male pairings in five different Scalpellum species, and one other species where the status of the hermaphrodite organism was uncertain. However, he said it was Scalpellum vulgare that he dissected first.

42 They were both outwardly very similar. Up to 1849, Darwin only refers to one species when discussing the Ibla genus, Ibla cumingii (e.g., to John Herschel, 11 May 1848: “The genus Ibla is a Cirripede or Barnacle... The Ibla is a quite small animal from the Philippines." CCD 4, 142; to A.A. Gould, 20 August 1849: "The Ibla is a species (not published) which I have named I. Cumingii \& was found in numbers by Mr Cuming at the Philippines: I have never seen it from elsewhere, except the specimen from Tavoy sent by you: it is in some Anatomical respects, perhaps the most interesting cirripede in the world." CCD 4, 249-250.)

${ }^{43}$ C.R. Darwin to A. Hancock, 8 June 1851: "Now that I am in the way of begging favours, I will ask conditionally another: you once sent me a spirited sketch of an Ibla from Australia: have you more than one or two specimens: I have the greatest wish to possess the very base of the peduncle still attached to whatever it adheres, especially if the surface be smooth: it is too long a story to tell why, but hereafter if you look at my monograph you will admit the importance of the point." CCD 5, 41-42. See also C.R. Darwin to J.S. Disnurr, 13 June 1851, CCD 5, 45-46. 
were collected at different times of year, their developmental lifecycle was made far more apparent. Thus Darwin could be more certain in his judgments about them. So Darwin may well have examined Ibla quadrivalvis prior to Scalpellum vulgare. However, the limited number of Ibla quadrivalvis specimens may have made it hard to be sure of the identity of the curious organisms attached to this hermaphrodite. Perhaps Darwin was only then able to conclusively establish a hermaphrodite-male pairing in Scalpellum vulgare. ${ }^{44}$ If this was the case, Darwin's letter to Hooker represented a celebration of confirmation rather than discovery. ${ }^{45}$ But against this possibility, there was still a curious sense of "astonishment" in Darwin's published account of the complementary males of Scalpellum vulgare, even though he had purportedly first seen such males in Ibla quadrivalvis. ${ }^{46}$

This brings us to the second reasonable possibility, one that is certainly more interesting, and potentially controversial. Here we have to take a big leap; we have to believe that Darwin deliberately misrepresented his research process and its chronology in Living Cirripedia, Volume I. As before, the species Darwin was referring to with Hooker were Ibla cumingii and Scalpellum vulgare. He had first spotted this more usual form of sexual differentiation in this Ibla species. But these Ibla cumingii males were a revelation: they were remarkably small, very rudimentary and they appeared to be parasitically attached to the female. In the wake of this eye-opening spectacle and prompted by his species theory that suggested he might see more ancient, transitional forms of differentiation in a nearby branch, Darwin performed perhaps the first of a number of double-takes that would punctuate the project. Darwin looked again at the closely related Scalpellum specimens he had discarded months ago. Perhaps those microscopic organisms clinging to this hermaphrodite cirripede were not the annoying parasites he had first dismissed them as? And perhaps that was why he was so animated with Hooker: he had discovered something even more surprising and new than the sexual differentiation he found in Ibla cumingii, and his species theory had helped him do it! Its predictions had helped him 'see' what he could not 'see' previously and avoid a potentially embarrassing oversight. If this is the case, Darwin's letter to Hooker was animated by a complex set of emotions - the excitement of discovery, mixed with vindication and relief.

In the absence of clinching evidence, both these possibilities seem realistic. But most of the evidence points to the second possibility. Either way, Darwin's published account was a somewhat 'massaged' one. It would hardly be the first time a prominent scientist misrepresented the often haphazard and serendipitous nature of their work and its inspirations.

\footnotetext{
${ }^{44}$ Darwin later reported to Hooker that he did such confirmatory work in October 1848. See CCD 4, 168170.

${ }^{45}$ Note Darwin's use of the phrase "I now can show" when he first wrote of his findings to Hooker. In this case, Darwin's species theory boasting would be based more on his theory's capacity to help correct his preliminary assessment of Scalpellum vulgare.

${ }^{46}$ See Darwin, 1854, p. 232.
} 
Reconstruction of the research process in ways that emphasize the orderly and the rational have long been known to be an endemic feature of public record accounts. The disconnect between archive-sourced chronicles of the research process and later public accounts was a key facet of the distinction made between the context of discovery and the context of justification. It is a distinction that dates back to Hans Reichenbach's work in the 1930s, and it dominated mid-20 th century philosophy of science. ${ }^{47}$ Moreover, the purpose here is not to impugn Darwin's honesty; his good reputation is all the more remarkable and well-deserved given the extent to which his private papers have been so forensically scrutinized. It's the nature of Darwin's relatively innocuous public record fudging that is interesting, not to mention the motivations behind it.

Darwin's Cirripedia volumes omitted any contribution his species theory might have made to his taxonomic work. All four of his barnacle volumes were scrupulously silent on that score. His transformist views remained a tightly enfolded aspect of his approach to systematics, for he was still years away from publishing Origin. ${ }^{48}$ Was Darwin prepared to engage in a certain amount of revisionism in order to obscure his heterodox inclinations? Certainly he did want to suggest that his discoveries and conclusions were purely empirical, one observation leading to another. Speculative preconceptions had no place in this version of the research process - especially not those based on the scientifically disreputable, if not scandalous, notion of transmutation. Darwin would increasingly cultivate a humble, evidence-driven persona during his career, particularly in his memoirs, in keeping with a nascent professionalism that emphasized the honest empirical toil of scientific work. Darwin was fond of telling self-depreciating stories against himself, as long as they did not make him appear too bumbling. But al Diabolo indeed! It

${ }^{47}$ The notion that public reports tended to knowingly misrepresent the research process gained a popular foothold with Peter Medawar's famous 1963 radio talk: "Is the Scientific Paper a Fraud." Medawar's main concern was that the scientific paper's conventions serve to misrepresent the research process as an orderly inductive exercise where pre-conceived expectations and ad hoc strategies had no role.

${ }^{48}$ And it seems that Darwin was prepared to be a little economical with the truth to keep his species theory under wraps, contra to van Wyhe (2007) who suggested he took no great steps to hide his transformist leanings. See Anonymous Author(s), "Exile on Luxted Road: The Historiography of "Darwin's Delay" and Why it Matters," forthcoming. Darwin's barnacle volumes assiduously maintained this discipline to the end, even when he must have been tempted to break cover. Richmond (1988, p. 399) cited one passage from Living Cirripedia, Volume II as evidence of his cryptic transformist reasoning: "In the series of facts now given, we have one curious illustration more to the many already known, how gradually nature changes from one condition to the other,-in this case from bisexuality to unisexuality." (Darwin, 1854, p. 29.) The word "change" was one of his most tantalizingly explicit clues of his transformist theorizing in these volumes. But it was still compatible with a special creation viewpoint, given that such a viewpoint could encompass the belief that "all gaps in the chain of nature would be filled up, if the structure of every extinct and existing creature were known..." (Darwin, 1854, p. 151.) 
seems Darwin was being a bit of devil here, and not just in terms of his somewhat facetious boastfulness to his good friend Joseph Hooker. ${ }^{49}$

\section{Beaten to the Punch}

Energized and engaged by these findings, Darwin worked through genus after genus of Cirripedia until ill health began to hold him up late in 1848. Darwin entertained his colleagues with his news of the transgressive aspects of barnacle reproduction. He prodded the conservative and upright botanist John Henslow with news of these subordinated male barnacles who "become parasitic within the sack of the female ... fixed \& half embedded in the flesh of their wives they pass their whole lives \& can never move again." 50 They had a rudimentary structure that matched their limited life and purpose, he told Hooker, for they had "no mouth or stomach" but develop "great testis!" 51 Conversely the females enjoyed a unique polyandry: "I do not know of any other case where a female invariably has two husbands ... Truly the schemes \& wonders of nature are illimitable." 52 Darwin might have teased his peers, but they were not the only ones being challenged by the astonishing realities of nature.

Meanwhile Darwin's priority claim over the kind of burrowing barnacle that "Mr. Arthrobalanus" represented would be trumped by Albany Hancock in 1849. The Newcastlebred Hancock was a solicitor turned naturalist. He had made a much more domestic kind of discovery: his new barnacle had been found off the coast off Durham, right under English naturalists' noses. Hancock named his species Alcippe lampas. He went on to suggest that not only did it represent a new genus (Alcippe), but a whole new order, which he named Cryptosomata. ${ }^{53}$ But Alcippe lampas shared many of the same characteristics as "Mr. Arthrobalanus," for it too burrowed or bored its way into its gastropod host, and had no shell. Alcippe lampas made its home in the columella of whelk shells, Buccinum undatum and Fusus antiquus, gastropod shells often later occupied by hermit crabs.

Hancock's sent his findings to be presented at the British Association in Birmingham in September 1849, which both Charles and his wife Emma attended. In his haste to publish, Hancock had done little in the way of internal anatomical analysis. So the reproductive features of Alcippe lampas were yet to be determined. Even so, Darwin immediately noticed Alcippe's

\footnotetext{
${ }^{49}$ Having breathlessly recounted his barnacle discoveries and his species theory contribution to Hooker, the al Diabolo reference is typically self-depreciating and jocular. Darwin was suggesting that his good friend might be wearied of such prolix news and might wish that both his barnacle research and species theory went to hell.

${ }^{50}$ C.R. Darwin to J.S. Henslow, 1 April 1848, CCD 4, 127-128.

${ }^{51}$ C.R. Darwin to Hooker, 6 October 1848, CCD 4, 168-170.

${ }_{52}$ C.R. Darwin to C. Lyell, 2 September 1849, CCD 4, 251-253.

${ }_{53}$ Hancock, 1849.
} 
affinities with "Mr. Arthrobalanus," and made an impromptu speech to this effect following the presentation. ${ }^{54}$ Darwin was a little perturbed by Hancock's decision to create a new taxonomic order for it. He was suspicious of endless taxonomic splitting and "species mongering." Then without introduction, Darwin later wrote to Hancock with his concerns. They would have a long and fruitful exchange on Cirripedia and the characteristics of their novel specimens, especially in relation to the means by which they burrowed or bored their way into their host shells.

At this point, Darwin was still two years away from publishing the first of his lengthy barnacle volumes. He was already sitting on a range of exciting findings relating to sexual differentiation. Unable to contain himself, and perhaps as a hedge against competing priority claims, he had broadcast news of these novel findings and his growing expertise to key allies, and even to potential rivals. ${ }^{55}$ The previous year John Gray had given Darwin a bit of a scare by presenting two papers on new cirripedes that were closely allied to Ibla and Scalpellum. But after reassurances from Gray that this was just old work and that he would bow out in future, all was resolved. So the fact that someone else had beaten him to the punch on burrowing barnacles must have seemed like small beer at the time. But if he had known what both he and Hancock had missed, he might have been more worried.

\section{Oh the Irony}

As it turned out, Darwin's original Chilean specimen, the trigger for the epic project that delayed his return to species theorizing, was even more intriguing than he had thought. But Darwin did not ascertain this until very late in the project. What has not been clearly brought to the foreground by scholars are the ironies inherent in this story of very belated discovery.

Sensibly, Darwin had left his most problematic cases and profound judgments till last. After drafting an unpublished paper on this "little monster" late in 1846, he put "Mr. Arthrobalanus" aside for almost seven years and turned to other species. By the beginning of 1853, Darwin had, with a nod to Hancock's priority, renamed "Mr. Arthrobalanus" Cryptophialus minutus meaning hidden, flask-shaped and very small. The new name reflected his greater knowledge and the fact that he would situate it nowhere near the Balanidæ family branch. Darwin finally came to describe Alcippe lampas and Cryptophialus minutus at much the same time, early in 1853.

\footnotetext{
${ }^{54}$ It seems Darwin had initially had some issues with the reproductive organs of Alcippe lampas as well. Darwin (1854, p. 539) admitted that in the middle of the segment bearing the sixth pair of cirri in the female organism, "the fold is slightly prominent and pointed, and being most finely villose, I for some time looked at this projection as a rudiment of the probosciformed penis."

${ }_{55}$ Darwin didn't tend to hold back on his barnacle news. There was a range of proprietary and credentialing motivations behind this. See Anonymous Author(s), "Exile on Luxted Road The Historiography of "Darwin's Delay" and Why it Matters," forthcoming.
} 
But he was vexed to the very last about where to place them both. With self-conscious misgivings, he eventually opted to separate them, grouping Alcippe lampas with the Lepadidæ and creating the separate order Abdominalia for Cryptophialus minutus. ${ }^{56}$

Darwin dissected and described Cryptophialus minutus and Alcippe lampas almost in tandem in first few months of 1853. His Journal listed him as examining Alcippe, then Cryptophialus, then Alcippe again. Darwin wrote that he first noted that each of his Alcippe specimens sported many small parasitic organisms. But again he had to do a double-take:

Although having had some experience in the very anomalous forms which male cirripedes assume, yet when I first casually inspected these parasites under a weak lens, from their transparency, their elongated and lobed body, including an internal folded up organ, I actually threw them away, thinking that they were probably Bryozoa. ${ }^{57}$

Bryozoa, you may recall, is the common moss-like marine invertebrate that was the subject of Darwin's very first paper at Edinburgh. However, in looking again with his powerful compound eyepiece, perhaps just a few days later, Darwin saw something quite different: these attached organisms were actually Alcippe lampas males.

Darwin wrote to Hancock for confirmation on this score, shyly pointing to his previous findings with Ibla and Scalpellum to prompt Hancock to re-examine his specimens. Hancock agreed: these attached organisms were indeed males of the Alcippe lampas species. In congratulating Hancock, Darwin admitted: "though having had experience how diverse an aspect the males put on, I now know that I looked at a Male, during the first day or two, \& never dreamed it was a cirripede." 58 And somewhere in this process, but apparently after ascertaining the identity of the Alcippe lampas males, Darwin came to recognize that the rather curious specks clinging to his 1.5 $\mathrm{mm}$. Cryptophialus minutus were likewise tiny but very similar parasitic males. They were attached at the same point of the carapace (or "outer tunic") as they were in Alcippe, with a comparable globular shape and transparent membrane covering. ${ }^{59}$

\section{Strategic Confessions}

\footnotetext{
${ }^{56}$ Darwin's original Chilean specimen, Cryptophialus minutus, is now grouped within a distinct order known as Acrothoracica in the Cirripedia infraclass. This sizeable order encompasses all the burrowing barnacles, including Hancock's Alcippe lampas (now known as Trypetesa lampas). All tend to be tiny (i.e., average $1 \mathrm{~mm}$.) and embed themselves in calcareous substrates (e.g., limestone, corals, and mollusc shells). Many other species have been added to the still-valid Cryptophialus genus. See Deutsch (2009) for an analysis of Darwin's reasoning behind his decision to separate Alcippe and Cryptophialus.

${ }^{57}$ Darwin, 1854, p. 555.

${ }_{58}$ C.R. Darwin to A. Hancock, 10 February 1853, CCD 5, 114-115.

${ }^{59}$ Darwin said he finished with Cryptophialus minutus on 30 March 1853. This was after he reported observing the Alcippe males at the beginning of the year to Hancock. CCD 5, 126-127.
} 
So "Mr. Arthrobalanus" was, in terms of his notional anthropomorphic nickname, a Drag King, Lola in reverse. This "singular little fellow" was not a hermaphrodite at all. Even more than that, Cryptophialus minutus was amongst the most sexually differentiated of all his Cirripedia species, along with Alcippe lampas, Ibla cumingii and Scalpellum ornatum. The Cryptophialus female contained no male organs at all. Those dual penises he thought he had spotted in 1846 were, Darwin now decided, nothing of the kind - as his rather sheepish mea culpa in Living Cirripedia, Volume II made clear:

The singular tapering appendages ... arising dorsally from the second and third segments, differ from each other only by the upper one being smaller, less curled, and perhaps rather smoother. When first examining this animal, not knowing that it was female, and not finding a probosciformed penis, I concluded that these organs were of this nature,-an excusable mistake, considering their almost ringed structure, their somewhat constricted bases, the direction of their curvature, and their position in the midst of the ova within the sack. On careful examination, however, these appendages are seen not to be truly ringed or articulated, but are covered with transverse lines of scales, hirsute on their edges; these scales being less distinct, or even quite absent on the smooth upper portion; they do not include any muscles; they are imperforate at the apex, which is not furnished with bristles (as seems always to be the case with the probosciformed penis); and, lastly, they are lined by corium, but are not occupied by any vessel, gland, or organ of any kind. 60

These were some other kind of structure of uncertain purpose: "The only function which I can assign to these appendages, is that of aiding the retention of the ova within the sack ..." And it now looked like his female "Mr. Arthrobalanus" did have an ovisac after all, with Darwin admitting that he had likely overlooked the "excessively fine membrane which in other cirripedes unites the ova together, and so forms the ovigerous lamellæ." 61

Darwin had already noted the considerable proportions of the male reproductive organs of many barnacles. As Darwin remarked: "In ordinary Cirripedes the penis is long, articulated, and capable of varied movements, I presume for the purpose of impregnating each separate ovum."62 These relative proportions were even more exceptional for the much smaller separate males of the group, though they tended to be less so for those males complementing hermaphrodite species. But just to confound this picture, the male of Ibla cumingii lacked a penis altogether, since lying where the egg mass would be deposited it would not need one. However, the Cryptophialus minutus male was the most generously-endowed of the lot. He may have been tiny, the vastly smaller half of the smallest known cirripede. But in nature's most

${ }^{60}$ Darwin, 1854, pp. 574-5.

${ }^{61} \mathrm{Ibid} .$, p. 579.

${ }^{2}$ Darwin, 1851, pp. 201-202. There were many other remarks to this effect in both volumes. For example: "The penis in several (Acasta) species was remarkably long." (Darwin, 1854, p. 307). For more on the remarkable capabilities of these barnacle appendages see Barazandeh, et al., 2013. 
heroic case of over-compensation, he had a "wonderfully elongated" penis. ${ }^{63}$ Darwin unfurled some of them: they were the most extensive relative to size in all the animal kingdom, up to eight or nine times the organism's dimensions. Great lengths were needed to ensure survival, Darwin reasoned. With the male the size of an ova and with perhaps only a couple of males available to fertilize many eggs, this enormous reach ensured all tiny sperm reached their target eggs.

So evidence of sexual differentiation in Cirripedia had been available to Darwin for nearly 20 years, ever since the fateful day he picked up those shells containing "Mr. Arthrobalanus." When he finally described Cryptophialus minutus in 1854 in Living Cirripedia, Volume II, he noted that all the females, except the very young, had males attached. One cannot be absolutely certain whether Darwin had noticed those tiny males clinging to the female "Mr. Arthrobalanus." Surely he did. While these males were very small - specks to the naked eye they were quite visible under the most basic of microscopes. He must have noticed them but interpreted them as something else, possibly as Bryozoa as well. Darwin didn't correct his misapprehension until the very end, only divining the true nature of the Cryptophialus males after he had uncovered a range of males in other larger species. And even then, it seems he only did so after his repeated examinations of Hancock's Alcippe lampas early in 1853.

Interestingly, while Darwin acknowledged his initial slip-ups with regard to the males of Scalpellum (in Living Cirripedia, Volume I) and Alcippe (in Living Cirripedia, Volume II), he never explicitly did so with respect to "Mr. Arthrobalanus," his most potentially embarrassing misapprehension of all. Certainly there was nothing like a full disclosure of the convoluted journey he had gone on. In Living Cirripedia, Volume II he explained the difficulties of recognizing the male cirripedes he had discovered, replete with this curious admission:

So widely do some of them depart in every character from their class, that twice it has happened to me to examine specimens with a little care, and not even to suspect, until a long period afterwards, that these males were Cirripedes. ${ }^{64}$

Which two instances of initially overlooking the males was he referring to here? There were at least three such instances: in Scalpellum, in Alcippe, and in Cryptophialus. Even though he acknowledged he had at first not recognized the Alcippe males, perhaps he was not counting this as one of these two instances. He had fairly quickly ascertained they were the males of the Alcippe lampas species once he put them under his compound microscope, not some "long period" afterwards. This rather oblique allusion was the closest he came to admitting to the chronic scientific discourtesy he had bestowed upon his female Cryptophialus minutus. After all,

${ }^{63}$ Darwin, 1854, p. 584.

${ }^{64}$ Darwin, 1854, p. 23. 
"Mr. Arthrobalanus" was actually quite the lady of the group. Darwin otherwise swept his 20 year misapprehension under the carpet, and it has gone remarkably unheralded by historians. ${ }^{65}$

\section{Why didn't Darwin recognize them?}

Darwin's findings on sexual differentiation were perhaps the most important evidential payoff of the whole project. He certainly valued them: when sending colleagues complimentary copies of his lengthy tomes, he almost invariably directed their attention to these findings, never mind the long and tedious taxonomic descriptions. ${ }^{66}$ They were one of the key reasons he received a Royal Medal in 1853 for his efforts. And even if did not state it explicitly, finding such differentiation was on the agenda right from the beginning. So the fact that one of the most pronounced forms of sexual differentiation was right in front of him all those years was no small matter. Why did it take him so long to pick this up, to perform the necessary act of interpretative recognition? It all must have seemed obvious to him in hindsight.

While Darwin possessed considerable general knowledge of marine invertebrates, he was on a relatively steep learning curve in the early stages of the project as a Cirripedia specialist. Darwin was reasonably well-versed in the basics of homologies, affinities and analogies from the outset, and quickly read up on the descriptive literature general systematic principles. He also had keen appreciation of embryology as guiding methodological principle before he started, although he did not read the most recent work of Milne-Edwards till late 1846 and Brullé soon after, after he had put "Mr. Arthrobalanus" aside.

Darwin was more obviously a novice in practical terms, with only modest experience in dissection and microscopic analysis. He had been in the habit of sending out his Beagle haul for classification and analysis. But with the barnacles, Darwin was determined to do it all himself. He was not particularly well-equipped at first. When he first assessed "Mr. Arthrobalanus" late in 1846, he was still working with the simple microscope that he had taken with him on the Beagle and an old, outdated compound microscope. While his Beagle microscope was an

\footnotetext{
${ }^{65}$ Darwin scholars writing about his barnacle project mention some aspects of the "Mr. Arthrobalanus" story, without clearly outlining Darwin's initial misapprehensions and the chronology of his eventual correction. For example, Desmond and Moore note that the nickname of "Mr. Arthrobalanus" proved to be a misnomer, but imply that Darwin ascertained this soon after hearing of Hancock's Alcippe. See Desmond and Moore, p. 367. Others gloss over it, even in the context of analyzing Darwin's "insights and dreadful blunders" (Deutsch, 2009) or confuse some details (Castilla, 2009, p. 480). Stott (2003) does capture much of this story, but is inaccurate on several chronological and technical points; for example, the naming of "Arthrobalanus" (p. 83), and the species Darwin had to look at twice (p. 99). She claims that Darwin's initial examinations of 1846 led him to believe that "Mr. Arthrobalanus" was wholly male (p. 85, p. 99). This would imply Darwin had recognized sexual differentiation at the very beginning of the project. But it appears he did not actually do so until early 1848.

${ }^{66}$ This was an aspect Darwin also proudly pointed to in his autobiography. See Barlow, 1858, p. 118.
} 
expensive instrument when he acquired it, rapid technical improvements had rendered both instruments obsolete a decade and a half later. Darwin did not get his state-of-the-art compound instrument with achromatically corrected lenses till April 1847 - a "splendid plaything" he called it. He also updated his simple Beagle microscope with an instrument made to his specifications in January the following year. Hooker tutored him on dissection, mounting and description in this early phase, while William Carpenter advised him on the use of his new compound instrument. Only then did Darwin fully develop the methodical, stepwise approach working up though magnification levels in the manner advocated by his old mentor Robert Brown and Christian Ehrenberg. ${ }^{67}$ And in taking on the whole group late in 1847, he committed to full, definitive descriptions.

So a relative lack of knowledge, skill and equipment may serve as partial explanation for why Darwin got "Mr. Arthrobalanus" so wrong for so long. But it doesn't fully explain it. Darwin's "beloved barnacles" would never cease to flummox him - not for want of knowledge, experience or microscopic acuity. While he became far more skilled at dissection and analysis and gained an ever increasing appreciation of the enormous variation of Cirripedia morphology, he made the same kinds of mistakes again and again - even if he was quicker to correct them later on. Darwin still tended to overlook or misidentify the male cirripedes. His highly-trained eyes of early 1853 had the same kind of recognition problems he had at the beginning, despite what he had already found.

To be fair, Darwin was working with specimens drawn from a complex biological environment where interdependent relationships were common. They often exhibited multiple attached organisms that required prima facie discriminations: were they juvenile forms of this species? Or another species of parasitic Crustacea? Or were they epizoic (i.e., attached but not parasitic) "zoophytes" such as Bryozoa? Or were they something else? Overt morphology was a key initial means of making such discriminations, looking for affinities with the host cirripede species and related species, as opposed to affinities with other types of organisms. Site of attachment was also often a key indicator. Further investigation of internal anatomy and developmental patterns would confirm (or disconfirm) initial impressions. But the problem with the overlooked or misidentified males was that Darwin did not investigate further; his initial assessments repeatedly led him to disregard them as biological 'noise.' As he later admitted, he did not even suspect these attached organisms were the male half of the species, rather than some other parasitic or epizoic organism.

What made it so difficult to recognize what he was so keen to find? Part of the answer lies in the unusual nature of the sexual differentiation that cirripedes display. We still think of it as unusual, but it was even more shocking a century and a half ago. The uncommon nature of what Darwin was looking for consistently eluded the preconceptions and analogous precedents

${ }^{67}$ Jardine, 2009. 
that framed Darwin's observational set. As it turned out, Darwin had only the barest clues as to what he should have been on the watching out for. His species theory only made the most general conjectures about divergence from an ancestral hermaphrodite form. And no one had done a systematic investigation of internal structures of Cirripedia, so he had little specific literature to guide him. Heading into the project we know that Darwin was aware of potentially instructive examples of sexual differentiation in related Crustacea, particularly in the Lerneidæ where the much smaller males would cling to the females. But this analogy proved to be a limited one: Lernaea males were nowhere near as rudimentary as the Cirripedia males turned out to be, and were not seen as permanently attached. So even with such a priming precedent in his mind, Darwin was both stunned and delighted by what he eventually found amongst his cirripedes.

It seemed that this Victorian naturalist never dreamed that the males of a species could be so inferior in structure and so subordinate in function. In summarizing the characteristics of his Cirripedia males in Living Cirripedia, Volume II, Darwin wrote:

The Males, in the above four genera [Ibla, Scalpellum, Alcippe and Cryptophialus], present a wonderful range of structure; they are attached in the usual way by cement proceeding from the not-moulted antennæ of the pupa, to different parts, in the different species, of the female. These males are minute, often exceedingly minute, and consequently generally more than one is attached to a single female ... As the females are longer lived, successive crops of males, at each period of propagation, become attached to her. It is the females in the above genera which retain the characters of the genus, family, and order to which they belong; the males often departing widely from the normal type. Some of the males are rudimentary to a degree, which I believe can hardly be equalled in the whole animal kingdom; they may, in fact, be said to exist as mere bags of spermatozoa. ${ }^{6}$

In all the other respects the females dominated in terms of size, structure and functionality. The males tended to be so different that they were barely recognizable as the same species. They apparently lived for one purpose only, and not very long at that. And they appeared to be permanently attached in such a fashion as to resemble parasites. That was how Darwin originally described them in his correspondence and in Volume I of Living Cirripedia in 1851. By 1854, however, Darwin had determined the relationship between male and female was an epizoic one. Given that in several species the males had no mouth, stomach or anus, their short lives were sustained entirely by their relatively substantial fat deposits. The simple structure and circumscribed lives of the males lent a certain logic to the polyandrous arrangements most endured. Yet this was still an almost unprecedented fact - it certainly was to Darwin at the time

${ }_{68}$ Darwin, 1854, p. 23. 
- if not a little scandalous. Hancock's Alcippe lampas males were the most shamelessly extreme in this respect, with Darwin noting "as many as fourteen adhering on one female!"69

The shocking contrast between the male and female of the species was most pronounced amongst Cryptophialus and Alcippe. No wonder Darwin overlooked the presence of the tiny attached males when he first christened "Mr. Arthrobalanus." The Cryptophialus and Alcippe males:

consist of a mere bag, lined by a few muscles, enclosing an eye, and attached at the lower end by the pupal antennæ; it has an orifice at its upper end, and within it there lies coiled up, like a great worm, the probosciformed penis, and beneath it a single testis, with a single vesicula seminalis. These organs complete the whole organisation of the male; for there is no mouth, no stomach, no thorax, no abdomen, and no appendages or limbs of any kind. Yet all these parts are present in the female. I know of no other instance in the animal kingdom of such an amount of abortion. ${ }^{70}$

Only after finding such strange examples of sexual differentiation did Darwin look farther afield for analogies. In 1854 in Living Cirripedia, Volume II, he wrote:

In my volume on the Lepadidæ (p. 200) in searching for analogies for the permanently epizoic and rudimentary condition of the male Cirripedes, I quoted two cases, which I believe are now known not to be analogous; namely, the Syngamus trachealis of Von Siebold, and the worm-like Hectocotyle, which latter was quite lately supposed to be a male Cephalopod, but has now been ascertained to be only one of the arms of the male wonderfully adapted and organised as a sperm-receptacle. The Asplanchna, the mouthless male of a Rotifer, (p. 292) alone remains for me. ${ }^{71}$

The lone analogy to certain species of Rotifera that Darwin was drawing attention to still stands as a reasonably good one. This phylum of microscopic pseudocoelomate marine invertebrates first described in the late 1600s - probably exceeds the Cirripedia in their diversity and the strangeness of their sexual arrangements. Most are exclusively female and reproduce parthenogenetically (i.e., asexually without fertilization). ${ }^{72}$ However, some genera, such as the Asplanchna that Darwin was pointing to, have very rudimentary, short-lived males and thus also reproduce sexually.

There was of course no precedent in the animal kingdom for the complemental males that accompanied certain hermaphrodite cirripedes. As Darwin noted, these complementary males were akin to reproductive backups, the extra 'kept husbands' of the hermaphrodite host. A

${ }^{69}$ Ibid.

${ }^{70} \mathrm{Ibid}$.

${ }^{71}$ Ibid.

72 For example, bdelloid rotifers have apparently persisted without having had sex for millions of years, a fact long considered 'scandalous' by evolutionary biologists because it challenged the view that the loss of sexual reproduction was an evolutionary dead end. But recent research has suggested they may engage in sex on rare, cryptic occasions. See Flot, et al., 2013. 
handful of other unrelated species exhibiting such pairings have since been identified in the years since, but such an arrangement is still regarded as decidedly rare. ${ }^{73}$

Not only were aspects of the sexual differentiation of cirripedes quite outside known zoological boundaries, they were at odds with Victorian notions of gender roles and family structures. Many naturalists of the era found themselves challenged by what nature had to offer; Darwin was hardly alone in this. ${ }^{74}$ Without going beyond what we know of Darwin's species theorizing and his grasp of the zoological literature, it is apparent that he entertained ad hoc expectations that had to be overridden time and time again. The convoluted path to his 'discoveries' was testimony to the difficulties. We can be certain that Darwin first identified the existence of male cirripedes in Ibla cumingii late in March 1848. But we also know that at least two examples of sexual differentiation (Cryptophialus minutus and Scalpellum vulgare) had already come across his work bench, with Darwin none the wiser. But certain features of Ibla cumingii made the male of the species males easier to recognize. One should note that in contrast to more intrepid field researchers like Thompson, Darwin did not generally work with live specimens. But the plentiful supply of Ibla cumingii specimens made it possible to observe the consistent presence of these 'parasites' and follow their developmental sequence. More importantly, the Ibla cumingii host organism was reasonably large and easy to dissect, and it was clearly unisexual. Darwin was able to quickly ascertain that it only had female reproductive organs. This was the strongest possible hint to investigate further, for it implied the necessity of separate males. And there they were: tiny, rudimentary, and right in front of him. But even after such a clear and

instructive precedent, it was still not smooth sailing. Nothing could quite prepare Darwin for the strange forms these males took.

(Insert Diagrams 1 and 2 about here)

\section{Thrilling Vindication or Perplexing Conundrum?}

\footnotetext{
73 See Weeks, Benvenuto and Reed, 2006.

${ }^{74}$ As Harper (2009) noted, the strange variety in the reproductive arrangements of the invertebrates challenged $19^{\text {th }}$ century naturalists' underlying social assumptions. In a realm least like that of the human, male forms were not necessarily stable or even necessary, for it was discovered that successive generations of some species alternating between sexual and asexual reproduction. Harper argued that Japetus Steenstrup's (1845) interpretation of alternating generations can be read as an attempt to impose a gendered order over nature. Steenstrup went as far as denying the existence of hermaphroditism altogether, arguing that males and females were of such contrasting natures that it was not possible for them to be united in one individual. According to Steenstrup, most naturalists of the era had misinterpreted the sex organs of 'hermaphrodite' species. For instance, he suggested the testicular organs of 'hermaphrodite' cirripedes were actually only a sperm receptacles for the female. Darwin dismissed Steenstrup's 1846 treatise, which he did not read until November 1850, as a rather "wild Memoir." C.R. Darwin to A. Hancock, 10 January 1953, CCD 5, 110-11.
} 
As a field-driven credentialing exercise, Darwin's barnacle project was inspired by a desire to tacitly demonstrate the righteousness of a "natural classification" based on the principle of descent through modification. Darwin scholars such as Richmond, Desmond and Moore, Browne and Stott have all suggested that Darwin's discoveries on the sexual differentiation in barnacles furnished him with a greater understanding of rudimentary and abortive organs in particular, and vindicated his species theory more generally. ${ }^{75}$ Darwin had long conjectured that there would be transitional sexually-differentiated forms. But theoretical conjectures were one thing, their wondrous and revealing instantiation were definitely another. The paradoxical nature of the differentiation Darwin found posed as many questions as it answered.

Darwin's species theorizing provided only vague indications of how sexual differentiation proceeded in terms of intermediary stages. Given what he had written in his notebooks and theory drafts, Darwin probably imagined a gradual process of differentiation from an ancestral hermaphrodite form. He probably envisaged finding evidence of a more symmetrical, ordered progression: relatively similar hermaphrodites with organs of one sex or the other exhibiting graded levels of abortion giving way to more advanced examples of wholly male and female forms. The extremely basic morphology of the males was a huge surprise, one that proved theoretically problematic. Darwin repeatedly drew attention to the rudimentary morphology of the males in his Living Cirripedia volumes. In some species, this feature was less marked. The complementary males of three hermaphrodite species of Scalpellum (Peronii, villosum and rostratum) were developed to a point where they otherwise resembled immature versions of some other genus that might be allotted a whole new order. ${ }^{76}$ But the anatomical composition of the males in the other seven differentiated species - which included all the female-male pairings and some of the hermaphrodite-male pairings - was so rudimentary they hardly looked like cirripedes at all. The only well-developed thing about them were their sex organs. This was clearly not what Darwin anticipated, and probably the main reason he repeatedly overlooked them.

More than this, Darwin's barnacles exhibited a paradoxical mix of intermediary and advanced forms of differentiation and abortion. For a start, only a subset of species showed any sexual differentiation, suggesting an emerging process at the level of the group as a whole. The hermaphrodite, hermaphrodite-male and female-male pairings certainly did resemble a transitional sequence. And the hermaphrodite-male pairings did indeed appear to represent an intermediary stage of differentiation. They showed theoretically-expected forms of abortion and development, with the male organs of the hermaphrodites shrunken and the reproductive organs of the complementary males less impressive than those of the other males (the penisbereft Ibla cumingii notwithstanding). But the overall morphology of the separate males of the female-male pairings tended to be more rudimentary than that of the complementary males of

75 Richmond, 1988; Desmond and Moore, 1991; Brown, 1995.

${ }^{76}$ Darwin, 1851, p. 291. 
the hermaphrodite-male pairings. ${ }^{77}$ This presented quite a conundrum. Darwin's thinking was guided by the evolutionary parallels he derived from John Hunter's assertion that the individual development of each sex was characterized by a differentiation from a common hermaphroditic state. If the series represented an emerging process of differentiation, how could Darwin explain the more advanced state of abortion these separate males displayed? From Darwin's transformist perspective, the basic structure of the separate males suggested a regression had occurred from a previously more developed separate or complementary male organism. Otherwise the series could just as easily be interpreted in the opposite direction as representing a process of reversion from separate sexes to hermaphrodite forms. In his final Living Cirripedia volume, Darwin played his theoretical cards close to his chest, as he generally did at this stage, merely citing his findings as a "curious illustration ... [of] how gradually nature changes from one condition to the other, - in this case from bisexuality to unisexuality." 78

Soon after completing the last of his Cirripedia volumes in 1854, Darwin reworked the scope of his principle of divergence to better explain branching diversification and the absence of transitional forms. It is not clear whether this shift in his thinking could be directly tied to his barnacle work. Commencing his "big species book" in 1856, Darwin tentatively tackled the sexual differentiation he had found in barnacles in a chapter on the "difficulties" of the theory. Given that Darwin assumed that the evolution of separate sexes was a one-way process of differentiation from ancestral hermaphrodite forms, he suggested that the partial differentiation he observed did indeed represent a transitional process. But he hardly came to grips with the more paradoxical aspects of the series as a whole. The hermaphrodite-male pairs were merely cited as an intermediary stage that showed "how unexpected a manner nature can effect a transition." From this stage, a separation of the sexes could "easily" be effected, wherein these complementary males would subsequently "assume the full dignity of the male sex." 79 Cirripedes did not feature particularly prominently in the rushed abstracted version that was Origin. ${ }^{80}$

\footnotetext{
77 This generalization holds both within and between genera exhibiting sexual differentiation. According to Darwin's descriptions, the complimentary males of Ibla and Scalpellum species tended to be larger and more complex than the separate males of the same genera. Comparing across genera/family/order divisions - problematic as that may be - the complimentary males also tended to be less rudimentary than the separate males. For those genera with separate males only (i.e., Alcippe and Cryptophialus), the males exhibited some of the most advanced forms of abortion. See Darwin, 1851, 1854.

${ }^{78}$ Darwin, 1854, p. 23. Darwin's liberal use of the term "abortion" in reference to his male barnacles was ambiguous, but certainly in keeping with the static meanings of comparative anatomy, as opposed to the transformist implications we might read into it today.

79 Darwin, 1856-1858, pp. 362-363.

80 The most pertinent comment Darwin in Origin made about Cirripedia sexual dimorphism was to characterize the male cirripedes as "retrograde." Darwin, 1859, p. 441.
} 
There would still be much work to do to on the concept of sexual selection to help explain sexual dimorphism and secondary sex characteristics. But Darwin's "beloved barnacles" would remain conspicuous by their relative absence from these discussions - surprising given the time and effort he invested in them. It seems the sense of thrilling vindication he initially felt gave way to something far more perplexing and inconvenient. It would prove difficult to reconcile the pathetically 'parasitic,' separate males with the concept of sexual selection he would later develop, particularly his insistence that females were generally less developed and more "ancestral" than males. By definition, the 'choice pressure' exerted by sexual selection acted on late-age variation (i.e., on reproductively mature organisms). But Darwin also tended to think that natural selection acted on late-age variation as well, making the arrested development of the male barnacles difficult to account for. ${ }^{81}$

It would be Darwin's growing legion of post-Origin admirers that would help explain such anomalous instances, notably the brilliant German outsider-naturalist Fritz Müller. Müller's 1864 book Für Darwin (translated as Facts and Arguments for Darwin) focused on organisms insects and crustaceans - that undergo some of nature's most spectacular metamorphoses. Müller stressed that evolutionary divergence could occur at any developmental point, with each stage subject to selective pressure. ${ }^{82}$ Fast-forwarding to the present, the rudimentary morphology of "dwarf" male cirripedes is now thought to be their key selected advantage. Being relatively quick to develop (i.e., 10 days after settlement for the "dwarf" males compared to at least a year for the bigger and more complex hermaphrodite/females), a greater proportion survive to maturity, resulting in a surfeit of reproductively useful males. And in contrast to Darwin's assumptions, the evolutionary history of Cirripedia is not thought to be characterised by a simple one-way progression from hermaphroditism to separate sexes. Instead, recent research has attempted to spell out the conditions favoring transitions between the various sexual arrangements they display. ${ }^{83}$

\footnotetext{
${ }^{81}$ Richards, in press, Chapter 9.

82 Müller, 1869, Chapter XI.

83 Yusa, et al., (2012) suggested the evolutionary sequence of barnacle sexual differentiation is far more complex and flexible than Darwin ever imagined, exhibiting a tendency to switch back and forth between various arrangements. Moreover, barnacles are now renowned for their capacity to cross-fertilize, even as part of androdiecious (hermaphrodite-dwarf male) arrangements. See Yamaguchi, et al., 2012. Darwin was well aware that barnacles could cross-fertilize, curtesy of their wonderfully long and articulate penises. See Darwin, 1851, p. 61 and Darwin, 1854, p. 102, p. 197 and p. 271. Not only is their capacity (and preference) for cross-fertilization seen as the key to why they cluster, it is also thought to play a significant role in the sexual differentiation they exhibit. Hermaphroditism had generally been thought of as a function of low density, a lack opportunity or capacity to find mates. But it seems the opposite is the case for barnacles. It is the low-density, stalked species that tend to exhibit sexual separation. Separate or complementary males are thought of as a handy addition for these low-density species, since limited opportunities to cross-fertilize makes for "low sperm competition." See Yusa, et al., 2012.
} 
Darwin never formulated a full evolutionary account of the paradoxical aspects of barnacle sexual differentiation. But by the time of The Descent of Man in 1871, he wisely refrained from implying that the 'undignified' morphology of the males would eventually be remedied as part of the evolutionary process:

The Complemental males of certain cirripedes live like epiphytic plants either on the female or hermaphrodite form, and are destitute of a mouth and prehensile limbs. In these cases it is the male which has been modified and has lost certain important organs, which the other members of the same group possess. ${ }^{84}$

Beyond these issues lurked deeper and more profound questions about the origin and benefits of separate sexes and sexual reproduction. As Darwin would note, differentiated sexual reproduction automatically ruled out half the population from breeding and demanded much time and energy in finding mates. Given these obvious evolutionary costs, it begged the question of how it arose in the first place. While Darwin worried that the final cause of sexual reproduction might remain hidden in darkness, he would eventually assure himself that hybrid vigor was an "amply sufficient" explanation. ${ }^{85}$ Contemporary researchers still puzzle over this question, particularly in relation to the distinction between sexual and asexual reproduction. ${ }^{86}$

\section{Conclusions}

The story of the misunderstood "Mr. Arthrobalanus" is a little like that of Darwin's Galapagos finches; but it also departs from it in significant respects. In both cases, a reappraisal of his initial observations led to thrilling 'discoveries,' a theory-laden volte-face mediated by new knowledge and increasing technical acuity. But Darwin's transformist theorizing appeared to both help and hinder his quest to find sexual differentiation amongst cirripedes. While the evidential demands of his theory no doubt motivated him, its general implications made for potentially misleading expectations that only the most careful, repeated observation could overcome.

Darwin's barnacle volumes were sprinkled with stories of fumbling preliminary evaluations, but almost all had happy empirical endings. However, he was all but silent about his misadventures with "Mr. Arthrobalanus," just as he was about the transformist theorizing that guided his work and gave this story such piquancy. Those focusing on Darwin's barnacle work, especially the more technically-minded, might now ask: Why does this story matter as long as he got it right in the end? If this is all that matters, then what do we make of some of Darwin's findings that we now think of as wrong? Throughout the project it has been well documented

\footnotetext{
84 Darwin, 1871, p. 225.

${ }^{85}$ Darwin, 1876, p. 462.

${ }^{86}$ Zimmer, 2009.
} 
that Darwin continued to misinterpret aspects of the reproductive organs of the females, mistaking ovarian ducts as cementing apparatus. He was soon corrected by other researchers, and Darwin later admitted he had "blundered dreadfully." ${ }^{87}$ But Darwin also made a range of what we now agree were erroneous judgements similar in nature to those he initially made with the males of Scalpellum, Alcippe and Cryptophialus. For example, Darwin disregarded the Rhizocephala, the now well-established third Cirripedia order. Rhizocephala are a type of parasitic cirripede that lives on crustaceans and other cirripedes. Darwin apparently misinterpreted aspects of their anatomy, failing to pick up on non-homologous features that were nonetheless convergent with his Cirripedia. This led him to dismiss them as another type of non-Cirripedia parasite. ${ }^{88}$ Fritz Müller was again quick to alert Darwin to the significance and interesting features of Rhizocephala. ${ }^{89}$

Unlike the overlooked or misidentified males, these errors remained 'uncorrected.' How do we explain this? Darwin channeled his energies in a manner that reflected underlying interests and goals that went beyond the general demands of descriptive taxonomy. Transitional forms of sexual differentiation were a kind of confirmatory manna from heaven as far as his species theory went, something he was prepared to go to great lengths to ascertain. Correcting his initial misinterpretation of the males required much back-tracking, as well as painstaking dissection, embryological observation and comparative analysis - all in the context of a huge project that was dragging on and on. In contrast, Darwin's taxonomic judgments were more cavalier in areas without such weighty personal implications. At the end of the project, Darwin instituted a third order, the Apoda, based on a single specimen he dubbed Proteolepas bivincta. While he noted that the structure of this specimen was highly anomalous, he listed five reasons why it should be considered a cirripede, bolstered by the confidence his long project had given him. ${ }^{90}$ However, this species has never been found since. A re-examination of Darwin's original specimen has concluded it was not a cirripede at all but an Isopod crustacean that lives on cirripedes. ${ }^{91}$ Only by reconstructing the circumstances and motivations that framed Darwin's work can we escape from the contradictions inherent in accounting for Darwin's "new facts" and "dreadful blunders" by appealing to current standards of truth.

Finally, the story of "Mr. Arthrobalanus" evokes the counter-factual: what if Darwin had correctly identified the internal structures of his female Chilean specimen and spotted those attached males straight away. He might have been more pragmatic and quickly written up this novel finding, and then quit while he was ahead. However, I suspect the opposite effect would

\footnotetext{
${ }^{87}$ Barlow, 1958, p. 118.

88 Deutsch, 2010.

${ }^{89}$ Müller coined the name Rhizocephala for this group, but placed them alongside rather than within Darwin's sub-class of Cirripedia. See Müller, 1869, Chapter IX.

${ }^{90}$ Darwin, 1854, pp.589-605.

${ }^{91}$ Deutsch, 2010.
} 
be far more likely, judging by the way his findings on sexual differentiation early in 1848 energized and engaged him. There were also many other factors pushing him toward the fullscale study it would become. Instead of dithering for the best part of a year in 1847, I suspect he would have immediately taken up Gray's offer and charged full-steam ahead with the whole group. Having seen what his beloved barnacles offered as a case-study of evolution in action, the drawn-out, barnacle-focused delay would essentially remain.

\section{Acknowledgements}

I would like to thank Evelleen Richards and James Bradley for their comments on draft versions of this paper and for their feedback on the issues it raised. An earlier version of this paper was delivered at the Conference of the Australasian Association for the History, Philosophy and Social Studies of Science at the University of Melbourne in November 2015.

\section{References}

Anderson, L. I. and Lowe, M. 2010. "Charles W. Peach and Darwin's Barnacles." Journal of the History of Collections 22: 257-270.

Barazandeh, M., Davis, C. S., Neufeld, C. J., Coltman, D. W. and Palmer, A. R. 2013. "Something Darwin didn't know about Barnacles: Spermcast Mating in a Common Stalked Species." Proceedings of the Royal Society B 280: 2012-2919.

Barrett, P., P. J. Gautrey, S. Herbert, D. Kohn, and S. Smith, eds. 1987. Charles Darwin's Note-books, 18361844: Geology, Transmutation of Species, Metaphysical Enquiries. Ithaca: Cornell University Press.

Barlow, N., ed. 1958. The Autobiography of Charles Darwin: 1809-1882. London: Collins.

Blower, S. M. and Roughgarden, J. 1988. “Parasitic Castration: Host Species Preferences, Size-selectivity and Spatial Heterogeneity." Oecologia (Berlin) 75: 512-515.

Browne, E. J. 1995. Charles Darwin Voyaging: A Biography, Volume 1. Princeton: Princeton University Press.

Burkhardt, F. H. and S. Smith, eds. 1985-1988. The Correspondence of Charles Darwin, Volumes 1-4. Cambridge, UK: Cambridge University Press.

Burmeister, H. 1834. Beiträge zur Naturgeschichte der Rankenfüsser (Cirripedia). Berlin: G. Reimer.

Castilla, J. C. 2009. "Darwin Taxonomist: Barnacles and Shell Burrowing Barnacles." Revista Chilena de Historia Natural 82: 477-483.

Crisp, D. J. 1983. “Extending Darwin's Investigations on the Barnacle Life-history. Biological Journal of the Linnean Society 20: 73-83.

Darwin, C. R. 1851 [1852]. Living Cirripedia, Volume I: A Monograph on the Sub-Class Cirripedia, with Figures of all the Species, Lepadidae or Pedunculated Cirripedes. London: The Ray Society. 
- 1854 [1855]. Living Cirripedia, Volume II: A Monograph on the Sub-class Cirripedia, with Figures of all the Species, The Balanidae (or Sessile Cirripedes; the Verucidae, etc.). London: The Ray Society.

- 1856-1858 [1975] Natural Selection, (ed. R. C. Stauffer). Cambridge, UK: Cambridge University Press.

- 1859. On the Origin of Species by Means of Natural Selection, or the Preservation of Favoured Races in the Struggle for Life. London: John Murray.

- 1871. The Descent of Man, and Selection in Relation to Sex, Volume I. London: John Murray.

- 1876. The Effects of Cross and Self Fertilisation in the Vegetable Kingdom. London: John Murray.

Deutsch, J. S. 2009. “Darwin and the Cirripedes: Insights and Dreadful Blunders. Integrative Zoology 4: 316-322.

Desmond, A. and J. Moore. 1991. Darwin: The Life of a Tormented Evolutionist. New York: W.W. Norton and Company.

Flot, J.-F. et al., 2013. "Genomic Evidence for Ameiotic Evolution in the Bdelloid Rotifer Adineta vaga." Nature 500: 453-457.

Goodsir, H. D. S. 1843. "On the Sexes, Organs of Reproduction, and Mode of Development, of the Cirripedes." Edinburgh New Philosophical Journal 35: 88-104.

- 1844. "Notice of Observations on the Development of the Seminal Fluid and Organs of Generation in the Crustacea." Edinburgh New Philosophical Journal 36: 183-186.

Hancock, A. 1849. "Notice of the Occurrence on the British Coast of a Burrowing Barnacle belonging to a New Order of the Class Cirripedia." Annals and Magazine of Natural History 4: 305-314.

Harper, L. M. 2009. “'The Starfish that Burns': Gendering Jellyfish.” In Forces of Nature: Natural(-izing) Gender and Gender(-ing) Nature in the Discourses of Western Culture, eds. B. H. Hyner and P. M. Stearns, pp. 21-50. Cambridge: Cambridge Scholars.

Hodge, M. J. S. 1985. "Darwin as a Lifelong Generation Theorist." In The Darwinian Heritage, ed. D. Kohn, pp. 207-243. Princeton: Princeton University Press.

Hunter, J. 1840. Observations on Certain Parts of the Animal Economy with notes by Richard Owen. Philadelphia: Haswell, Barrington, and Haswell.

Jardine, B. 2009. "Between the Beagle and the Barnacle: Darwin's Microscopy, 1837-1854." Studies in History and Philosophy of Science 40: 382-395.

Karsten, H. 1845. "Disquisitio Microscopia et Chemica Hepatis et Bilis Crustaceorurn et Molluscorum." Nova acta, Academiae Caesareae Leopoldino Carolinae Gcrmanicae Naturae Curiosorum 21: 295-326.

Keynes, R. ed. 2000. Charles Darwin's Zoology Notes E Specimen Lists from H.M.S. Beagle. Cambridge: Cambridge University Press.

Lamarck, J. B. 1969 [1801]. Systeme des animaux sans vertebres. Bruxelles: Facsimile reprint by Culture et Civilisation. 
Love, A. C. 2002. "Darwin and 'Cirripedia' Prior to 1846: Exploring the Origins of the Barnacle Research." Journal of the History of Biology 35: 251-289.

MacLeay, W. S. 1819-1821. Horae Entomologicae: or, Essays on the Annulose Animals. London: S. Bagster. 1839.

- 1839. "Invertebratae." In Illustrations of the Zoology of South Africa, ed. A. Smith, pp. 1- 75. London: Smith, Elder and Co.

Mannouris, C. 2011. “Darwin's ‘Beloved Barnacles': Tough Lessons in Variation.” History and Philosophy of the Life Sciences 33: 51-70.

Medawar, P. 1963. “Is the Scientific Paper a Fraud?" Listener 70: 377-378

Müller, F. 1869. Facts and Arguments for Darwin, (trans. W.S. Dallas). London: John Murray.

Osler, E. 1826. "On the Burrowing and Boring Marine Animals." Philosophical Transactions of the Royal Society 116: 342-371.

Owen, R. 1843. Lectures on the Comparative Anatomy and Physiology of the Invertebrate Animals. London: Longman, Brown, Green, and Longmans.

Rainbow, P. S. 2011. “Charles Darwin and Marine Biology,” Marine Ecology 32 (Suppl. 1): 130-134.

Richmond, M. 1988. "Darwin's Study of the Cirripedia." In The Correspondence of Charles Darwin, Volume 4, eds. F. H. Burkhardt and S. Smith, pp. 388-409. Cambridge, UK: Cambridge University Press.

Richards, E. (In press). Sexing Selection: Darwin and the Making of Sexual Selection, University of Chicago Press.

Siebold, K. Th. E. von and Stannius, H. 1949. Nouveau Manuel d'Anatomie Comparée. Paris: à la Librairie Encyclopédique de Roret.

Sloan, P. R. 1985. "Darwin's Invertebrate Program, 1826-1836: Preconditions for Transformism." In The Darwinian Heritage, ed. D. Kohn, pp. 71-120. Princeton: Princeton University Press.

Steenstrup, J. J. S. 1845. On the Alternation of Generations; or The Propagation and Development of Animals through Alternate Generations, trans. G. Busk. London: Ray Society.

- 1846. Untersuchungen über das Vorkommen des Hermaphoditismus in der Natur. Greifswald: Creplin.

Stott, R. 2003. Darwin and the barnacle. New York: W.W. Norton.

Straus-Durckheim, H. 1819. "Memoire sur les Daphnia, de la classe des Crustaces." Memoires du Museum d'Histoire Naturelle 5: 380-425.

Thompson, J. V. 1835a. "Discovery of the Metamorphosis in the Second Type of the Cirripedes, viz. the Lepades, Completing the Natural History of these singular Animals, and Confirming Their Affinity with the Crustacea." Philosophical Transactions of the Royal Society 126: 355-358.

- 1835b. "On the Double Metamorphosis in the Decapodous Crustacea, exemplified in Cancer Maenas, LINN." Philosophical Transactions of the Royal Society 126: 359-362. 
- 1968 [1828-1834]. Zoological Researches and Illustrations or Natural History of Nondescript or Imperfectly Known Animals, Vol I, Part I. London: Facsimile reprint by Society for the Bibliography of Natural History.

Weeks, S. C., Benvenuto, C. and Reed, S. K. 2006. "When Males and Hermaphrodites Coexist: A Review of Androdioecy in Animals." Integrative and Comparative Biology 46: 449-464.

Winsor, M. P. 1969. "Barnacle Larvae in the Nineteenth Century: A Case Study in Taxonomic Theory." Journal of the History of Medicine and Allied Sciences 24: 294-309.

Van Wyhe, J. 2007. "Mind the Gap: Did Darwin Avoid Publishing His Theory for Many Years?" Notes and Records of the Royal Society of London 61: 177-205.

Yusa, Y., Yoshikawa1, M., Kitaura1, J., Kawane1, M., Ozaki1, Y., Yamato, S. and Høeg, J. T. 2012. "Adaptive Evolution of Sexual Systems in Pedunculate Barnacles." Proceedings of the Royal Society B 279: 959-966.

Yamaguchi, S., Charnov, E.L., Sawada, K. and Yusa, Y. 2012. "Sexual Systems and Life History of Barnacles: A Theoretical Perspective." Integrative and Comparative Biology 52: 356-365.

Zimmer, C. 2009. “On the Origin of Sexual Reproduction.” Science 324 (5932): 1254-1256. 

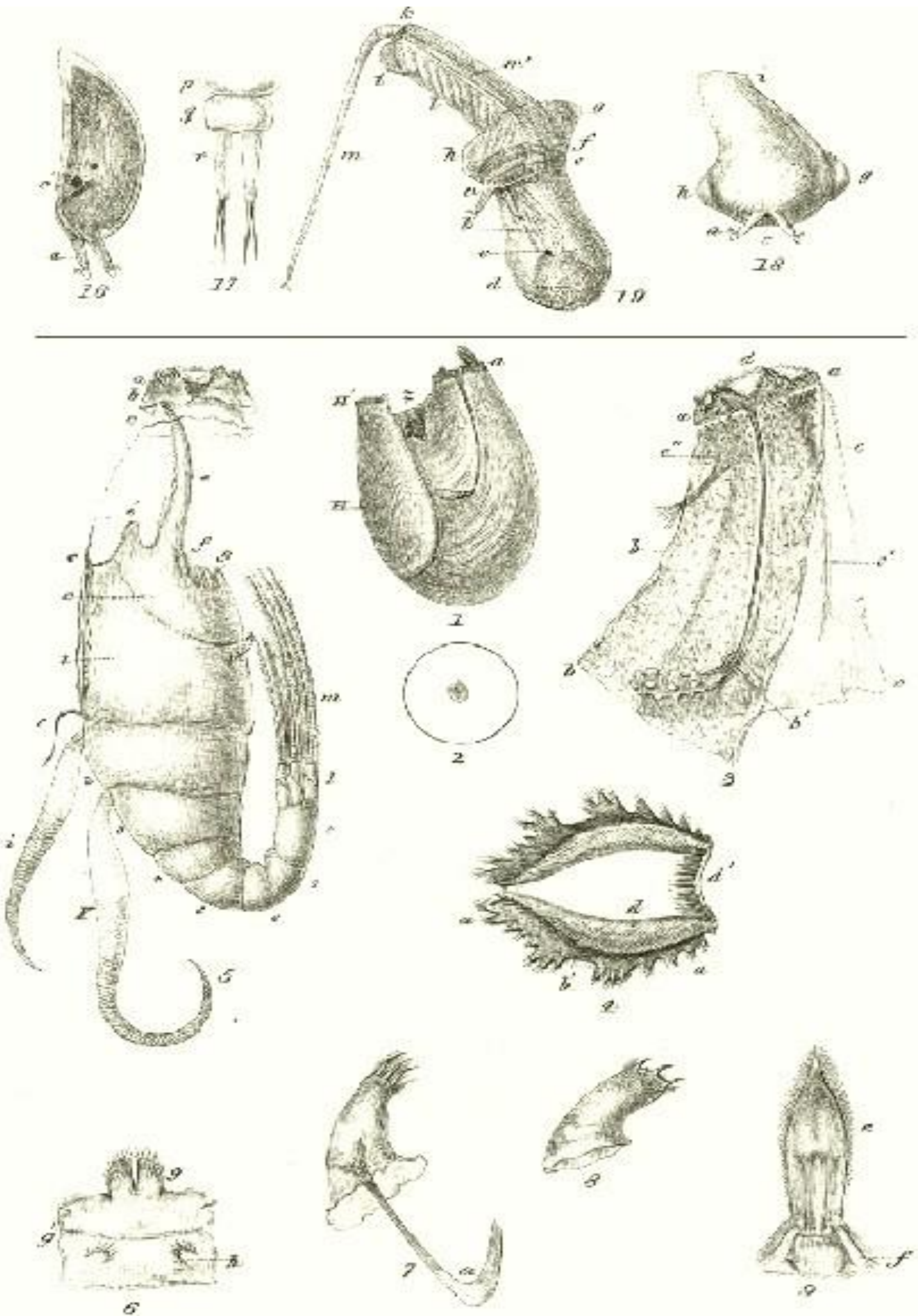


\section{Diagram 1}

Darwin, 1854, Plate 23.

Top row features Alcippe lampas males

16. Pupa of male Alcippe lampas

17. Abdomen of pupa Alcippe lampas

18. Alcippe lampas male immediately after metamorphosis

19. Alcippe lampas male when fully mature, with probosciformed penis shown exserted.

The bottom section of this plate features Cryptophialus minutus

1. Cryptophialus minutus female with an attached male on the upper portion of outer tunic

2. The above represented natural size where Cryptophialus minutus within a half inch circle

5. Cryptophialus minutus with outer tunic removed 

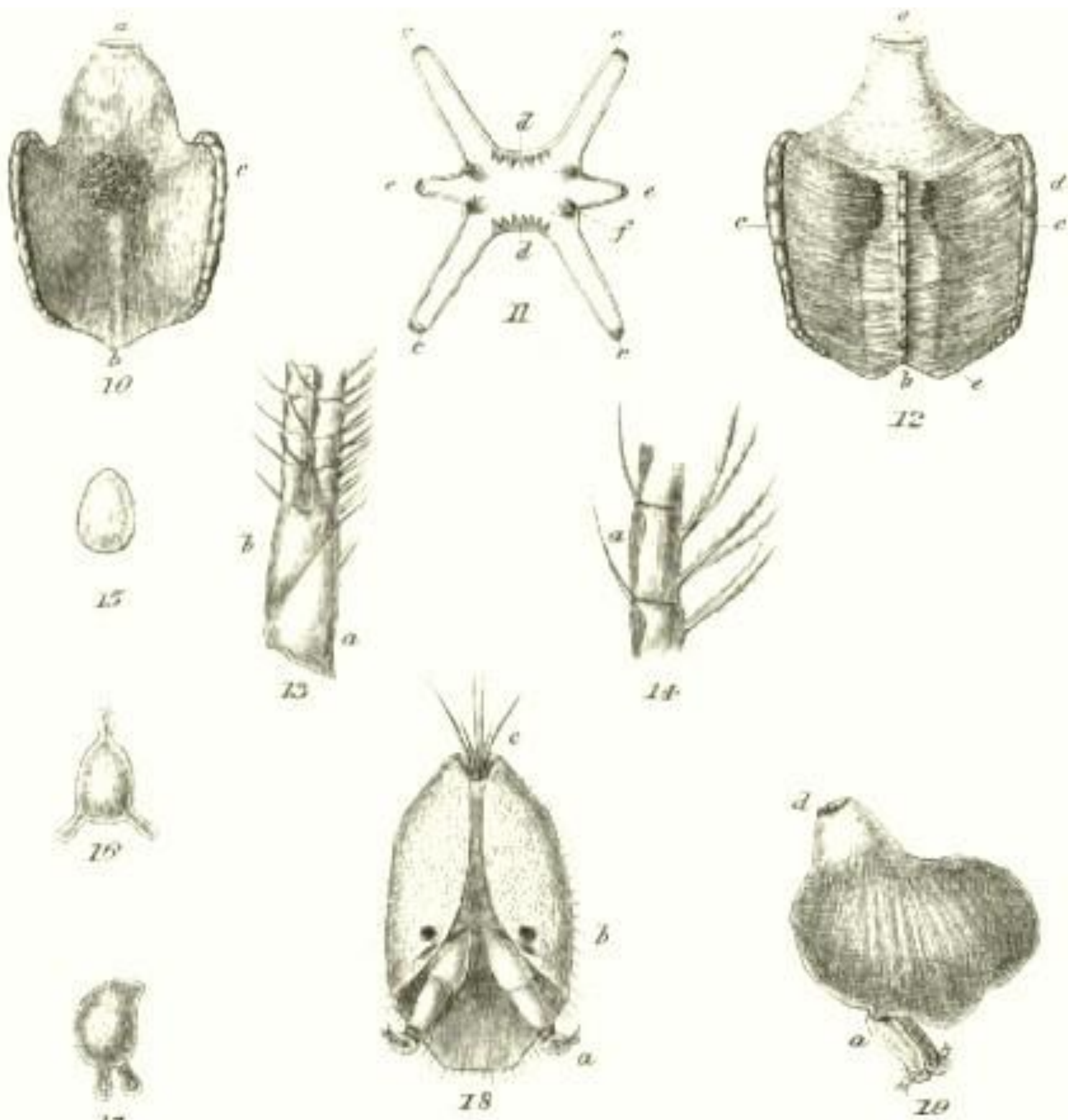

17 


\section{Diagram 2}

Darwin, 1854, Plate 24.

Cryptophialus minutus ovum, larva and male

15. Cryptophialus minutus ovum

16. Cryptophialus minutus egg-like larva in the first stage

17. Cryptophialus minutus larva in the second stage

18. Cryptophialus minutus larva in the last or pupal stage

19. Cryptophialus minutus male 


\section{University Library}

\section{- M M N E R VA A gateway to Melbourne's research publications}

Minerva Access is the Institutional Repository of The University of Melbourne

Author/s:

Buchanan, RD

Title:

Darwin's "Mr. Arthrobalanus": Sexual Differentiation, Evolutionary Destiny and the Expert Eye of the Beholder

Date:

2017-05-01

Citation:

Buchanan, R. D. (2017). Darwin's "Mr. Arthrobalanus": Sexual Differentiation, Evolutionary Destiny and the Expert Eye of the Beholder. JOURNAL OF THE HISTORY OF BIOLOGY, 50 (2), pp.315-355. https://doi.org/10.1007/s10739-016-9444-9.

Persistent Link:

http://hdl.handle.net/11343/283171 